\title{
The Development and Research of China Industrial Cluster Based on Supply Chain: A Case of Beijing-Tianjin-Hebei Tourism Destination
}

\author{
Zhang Le ${ }^{1, *}$ and Zhang Ning ${ }^{2}$ \\ ${ }^{1}$ School of Management, Yanching Institute of Technology; Heibei Langfang 065201, China; ${ }^{2}$ Humanities and Social \\ Sciences College, Agricultural University of Hebei Province; Heibei Baoding 071000, China
}

\begin{abstract}
The upgrading of industrial cluster is upgrading along the value chain, improving the added value of products, which is from low-end to high-end in the value chain. Industrial cluster is made up of one or several supply chain in a certain geographic area concentration, and has a coupling between them. The development of the Beijing-Tianjin-Hebei integration has entered a new stage of resource integration, and the carrier of resource integration is the advantage of industrial cluster. This paper starts from the connotation of tourism destination competitiveness, and puts forward this point of promoting the competitiveness of tourism destination based on supply chain industrial cluster. Through the analysis on the connotation and characteristics of supply chain, combing the tourism destination, the relationship between the supply chain and value chain, as a case study of Beijing-Tianjin-Hebei region extend to the regional tourism destination development, points out the further promotion of the supply chain network structure, management method and innovation mechanism, which provides effective ways for the upgrading of industrial cluster.
\end{abstract}

Keywords: Beijing-tianjin-hebei region, industrial cluster, resource integration, supply chain.

\section{INTRODUCTION}

Industrial cluster and enterprise agglomeration is industrial upgrading model of the high-end and most competitive advantage in the world today. About the research of industry cluster, as can be traced back to the end of the 19th century Marshall research on external economy theory, the 20th century, industrial cluster is blustery. In 1905, weber's industrial location theory, transaction costs theory of Kos and increasing return to scale theory of Krugman in 1934 and 1991, etc., from different angles on the formation and characteristics of the industry and internal mechanism was discussed and the research [1-4]. Along with economic development, industrial cluster around the world also gradually began to break out. Although the competitive advantage of industrial cluster is obvious, some early industrial clusters by the sheng and the failure, a declining but also the fact that does not dispute. A common feature of the decline of industrial cluster is slow development and not timely to achieve industrial upgrading. The manufacturing industry mainly shows the characteristics of clusters in China, abundant labor resources and low cost is the comparative advantage, which makes Chinese most of the cluster in the global value chain in the middle low valueadded production processing link, most of the cluster is still in the low end of the road in the development of industrial clusters [5-7]. From the value creation activities, profit comes mainly from the brand, the core technology of manufacturing, sales, service and logistics, etc., Chinese manufacturing enterprises lack the capability of the value-added of resources, low profit and high market risk.

\section{THE STARTING POINT OF INDUSTRIAL CLUS- TER UPGRADING}

According to the curve of global value chain (as shown in Fig. 1), combined with the location of the manufacturing industry cluster in China, it can be seen that the upgrading goal of industrial cluster. The upgrading of industrial cluster is the inevitable, where the key is to upgrade, how to upgrade [8]. To clear this problem, firstly solve where the starting point of the manufacturing industry cluster upgrading in China is. Along with the development of economic globalization, any industrial cluster is no longer a closed system, and cluster has been integrated into the global value chain. With the development of the industrial division, the product of the production process is broken into different stages, all kinds of activities can be included within an enterprise, also can be dispersed in each between enterprises, and can be gathered in a particular geographic area, also can spread the world. At the end of the $20^{\text {th }}$ century, many multinational manufacturers have production base will shift from developed countries to developing countries, it is particularly popular in labor-intensive industries, China's industrial clusters also extensively involved in the global value chain system.

According to the value creation process, the global value chain can be broken down into many link of value creation. The manufacturing clusters of different countries and regions, with their respective comparative advantages, have been into the global value chain and engage in the production activities in the value of the different segment. Gereff believes that each has a dominant player in the value chain, which plays a decisive role in the nature of the value chain. Lead enterprise in the global value chain, usually can obtain more 


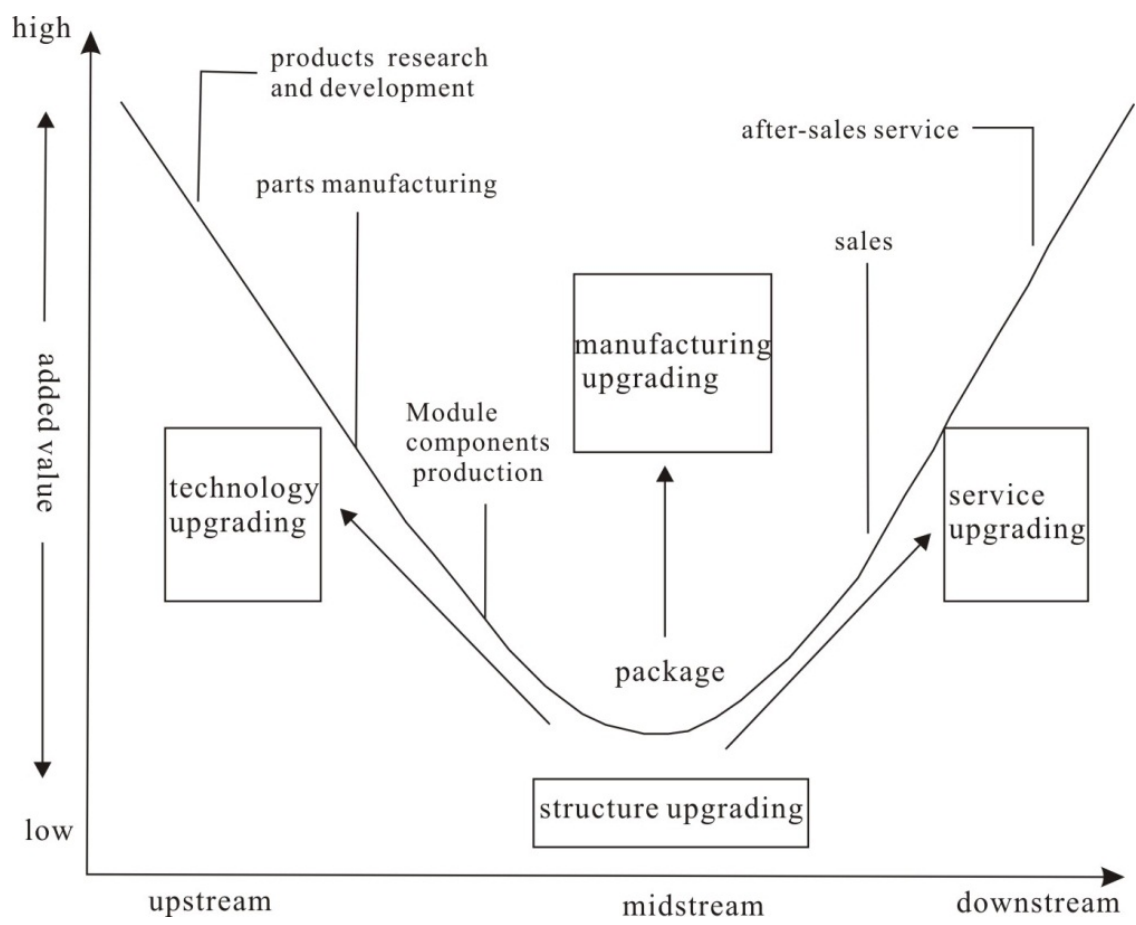

Fig. (1). The curve of industrial cluster upgrading based on value chain.

profits, so that to participate in the value chain of each enterprise income gap is obvious. On base of different dominant role, the global value chain can be divided into two types $[9,10]$ : one is that the buyer is driven, the Chinese shoe industry, textile and apparel, toys, hardware, small appliances and other labor-intensive industries with low value end products embedded the global value chain, become the transnational retail giant upstream products supplier. Another kind is driven by the manufacturers, plays a leading role in this model are the manufacturers, they have their own technology and brand advantage. Abundant labor resources and low cost is the comparative advantage of China's manufacturing industry, which makes our country such as automobiles, electronics, computers, machinery manufacturing industry cluster in the global value chain of the multinational manufacturers dominated on OEM production, non-core components supporting production or low value activities such as simple processing and assembly.

Local industrial clusters in China embeds in "buyer is driven" or "producer is driven" global value chain, are all in the low-end links of the value chain, the value creation activities or the provision of the final product depends on its resource advantage of cheap labor. The upgrading of industrial cluster is along value chain upgrading, improves the added value of products, in the value chain from low-end to high-end.

\section{SUPPLY CHAIN AND VALUE CHAIN}

\subsection{The Relation of Supply Chain and Value Chain}

In China, manufacturing industry cluster embeds in global value chain, at the same time, which has also embedded in the global supply chain. Providing us with the value chain analysis is the goal of an upgrade, but the way and the method of the upgrade need through the supply chain to achieve.
Around a commodity production forms a kind of transnational production organization system, the distribution of different scale enterprises, institutional organizations around the world in the production of an integrated network, thus formed the global value chain. Supply chain is around the core enterprise, through the control of information flow, logistics, cash flow, starting from the procurement of raw materials, made of intermediate products and final products, and finally by the sales network products to consumers' hands will suppliers, manufacturers, and distributors until the end user together as a whole function nets chain structure [11, 12]. Structurally, they are overlapping, cannot leave the specific enterprise and specific business process. In the two chains, there are logistics, information flow and cash flow. Supply chain and value chain are unified in the enterprise movement, also can be unified in around a product output of all business scope, as shown Fig. (2).

The core of value chain management is how to create value, improving business efficiency. With different link in the production process, an increase of value creation ability is the value chain to solve the main problem. And supply chain management is the core of the whole process of the supply-demand relationship between upstream and downstream, the chain of how to reduce operating costs, improves efficiency, and realizes the effective link between supply and demand. The former reflects the enterprise deeper content, such as business strategy, competitive advantage, which involves a number of intangible factors, such as the corporate philosophy, corporate culture, etc. Supply chain surface reflects the specific business operations, such as logistics, inventory, information flow, etc., but it's also a tactics and means of value chain management. The value chain decides supply chain and supply chain services, subjects to the value chain. The specific operation of the supply chain for a certain period reflect specific to the requirements of a value chain. 


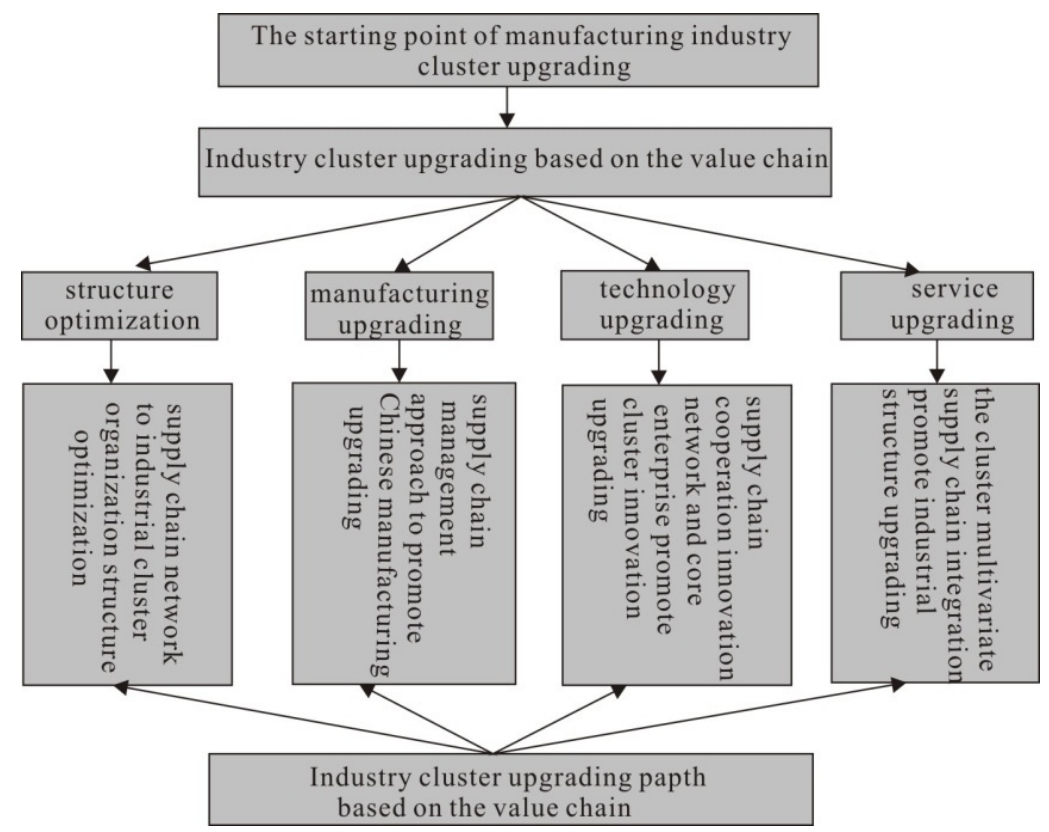

Fig. (2). Objectives and path of supply chain and value chain.

In the study of industrial cluster upgrading, based on the value chain perspective put forward the goal of upgrading, namely cluster upgrade evaluation basis, supply chain network structure, management method, the innovation mechanism for cluster upgrade path. Through the combination of the value chain and supply chain goal and path, building up China industry cluster upgrade system.

\subsection{The Coupling of Supply Chain and Value Chain}

The composition entity of industrial cluster, to some extent, is also the structure entity of supply chain. Industrial clusters by the specialization of similar or related industry by many enterprises and value chain related support enterprises, institutions, which is also the structure of the supply chain entities. Within the industry cluster around the leading industry, there are multiple supply chain network of industrial cluster is more than a supply chain. In the cluster is a group of interrelated enterprises and between enterprises with upstream and downstream the supply-demand relationship, have their own enterprise supply chain, and in which a single chain of section. Each single chain upstream and downstream enterprises internal supply chain cooperation, competition among enterprises of different single stranded. In addition to around the end product production and associated with enterprise, product supply chain enterprise provides professional services and other productive service enterprise effective connection, chain, service chain, technique, form a supply chain network.

\section{THE CONNOTATION OF TOURISM DESTINA- TION SUPPLY CHAIN}

\subsection{The Development of Supply Chain}

The generation and development of the tourism destination supply chain are inseparable of facing environmental change, of which the most influential two changes are economic globalization and the rapid development of informa- tion technology. Countries closer economic ties, the world economic development presents a "change one, the global trend," requirements tourism have rapid response ability to respond to environment change. Response ability enhancement is to enhance the premise of tourism supply chain flexibility production, tourism destinations facing market competition has been from the competition between enterprises and enterprises into the competition between supply chain and supply chain. The development of science and technology has broken the tourism enterprise competition cooperation of regional restrictions, increase the possibility of a tourism enterprise use of external resources, and provides the advanced means for tourism cooperation between enterprises. Around for the best partners, improve the competitiveness of this purpose, an enterprise of a fundamental change in the shape and boundary of tourism destination network supply chain system arises at the historic moment.

With the development of social economy, the demands of tourists begin to turn into individuation and diversification. They pay more attention to the value of product and to satisfy their way of life, hope to get customized products and services. This change in consumer behavior to the production and operation of tourism enterprises and destination development had a profound impact, tourism gradually from large-scale mass production to production to meet specific market demand differentiation, by the high yield production towards high value-added production. The emergence of the trend of tourism supply chain is put forward new challenges, including how to established for each product or customer group of separate supply chain and how to meet the market demand at the same time take advantage of economies of scale in the supply chain, etc.

\subsection{The Particularity of Supply Chain}

Tourism economic attribute determines the objective existence of the tourist destination commercial service supply chain, supply chain consists three main components of sup- 


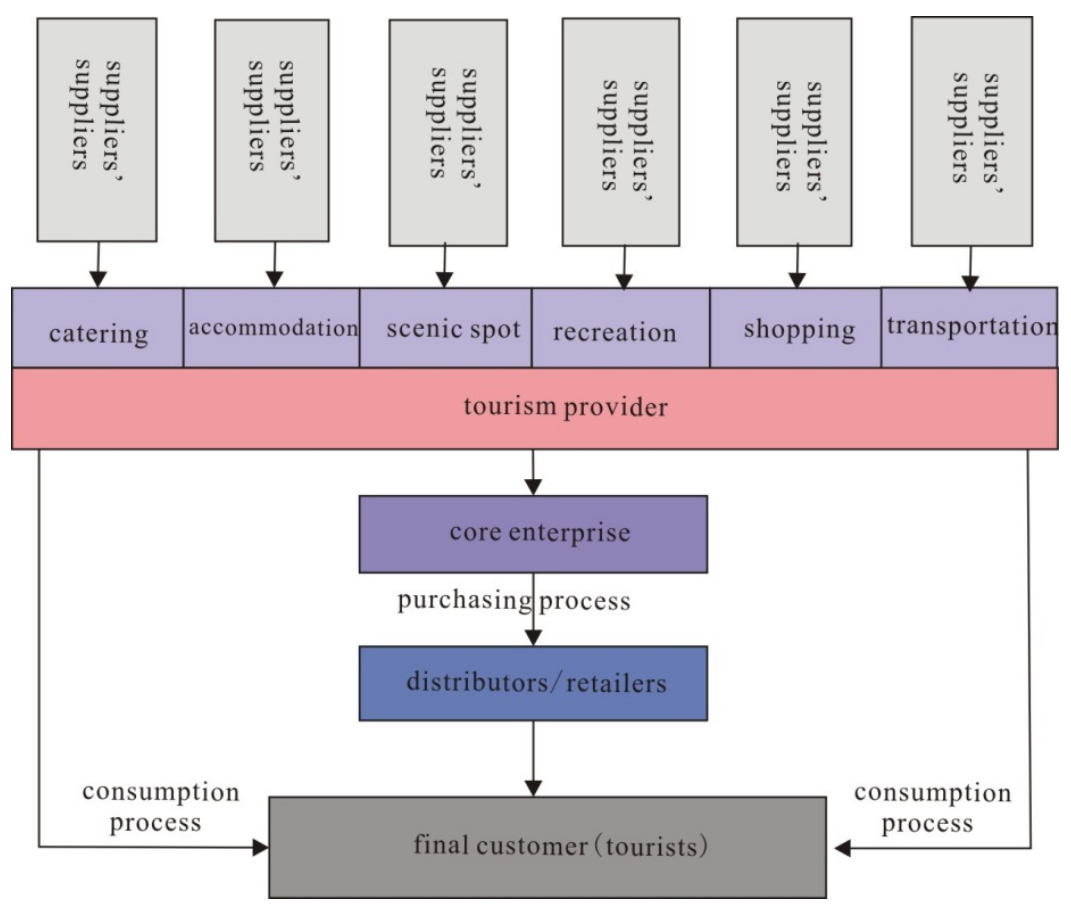

Fig. (3). The supply chain of tourist destination business services.

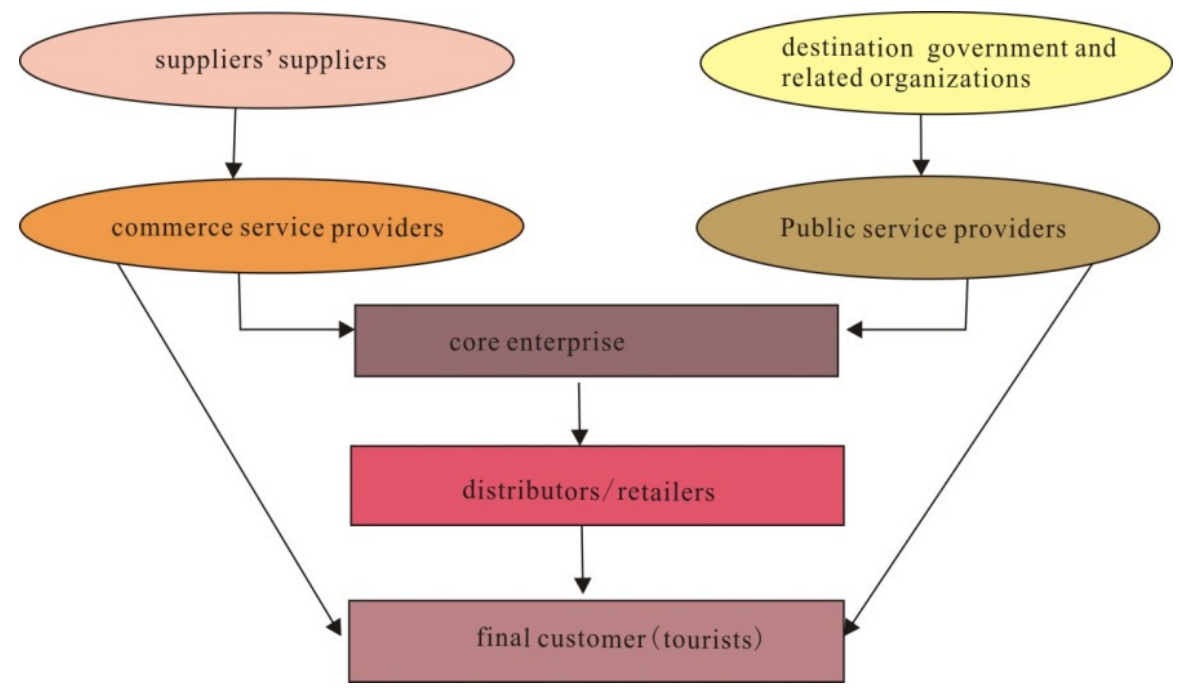

Fig. (4). Supply chain of tourist destination.

pliers, the core enterprise and customers. Because of the tourism product is a kind of intangible service products, the production and consumption have identity, and therefore, compared with the traditional manufacturing industry, the flow of the tourism supply chain products is not carried out along a single chain.

In manufacturing, products are transmitted along the chain of supplier $\rightarrow$ manufacturer $\rightarrow$ distributor $\rightarrow$ retailer $\rightarrow$ customer, customer only contact the final product of the supply chain, not across the core enterprise contact suppliers of semi-finished products. In the tourism supply chain, the customer to buy is the core enterprise to provide the complete tourism products, but in the process of consumption, in fact and all the component part of tourism products offered by travel suppliers direct contact, such as food and beverage, accommodation products, etc., as shown in Fig. (3).
Because the tourism product has integrated the fundamental features, determines the destination of integrated supply chain. Tourism products provide not only involve travel suppliers, at the same time, need to include health, postal telecommunications, Banks, insurance and other public service support, and the public service supply chain is an important part of tourism destination supply chain. It is important to note that the tourists and the public infrastructure and service providers still keep directly contact relationships, as shown in Fig. (4).

Due to the comprehensive of tourism destination supply chain, the suppliers involved in the complex, the level of development is uneven, the position and function of the supply chain also each are not identical, at the same time, these suppliers have direct contact with the customer and provide the corresponding services, the experience of tourists to the 
destination product depends on the quality of all of these services. Therefore, to improve the competitiveness of the tourism destination, we must pay attention to the quality level of a single supplier and the quality of adaptability between the node enterprises or organizations. Of these interconnected coordination and integration of business services and public services, realize the balanced development of the whole supply chain, to provide a tourist destination experience with quality guarantee products and ensure that tourists to the destination comprehensive satisfaction laid the foundation of ascension.

\section{A CASE ANALYSIS OF BEIJING-TIANJIN-HEBEI TOURIST DESTINATION}

Beijing-Tianjin-Hebei geographical position are closely linked, the category of tourism resources is rich and has each distinguishing feature and accessibility is strong, which has the natural advantages of regional tourism cooperation. In recent years, as the multi-strip inter-city highways and railways construction, and rapid transit system is gradually perfect in Beijing-Tianjin-Hebei metropolis circle, but the tourist cooperation of three places is still smaller scale, stronger optional and other issues. In order to further deepen the regional tourism cooperation, realizing a rational flow of factors of tourism economy between three and effective combination, we must integrate for three aspects of strategy, planning and operation of regional tourism destination supply chain, eventually, obtain regional tourism competitiveness ascension, as shown in Fig. (5).

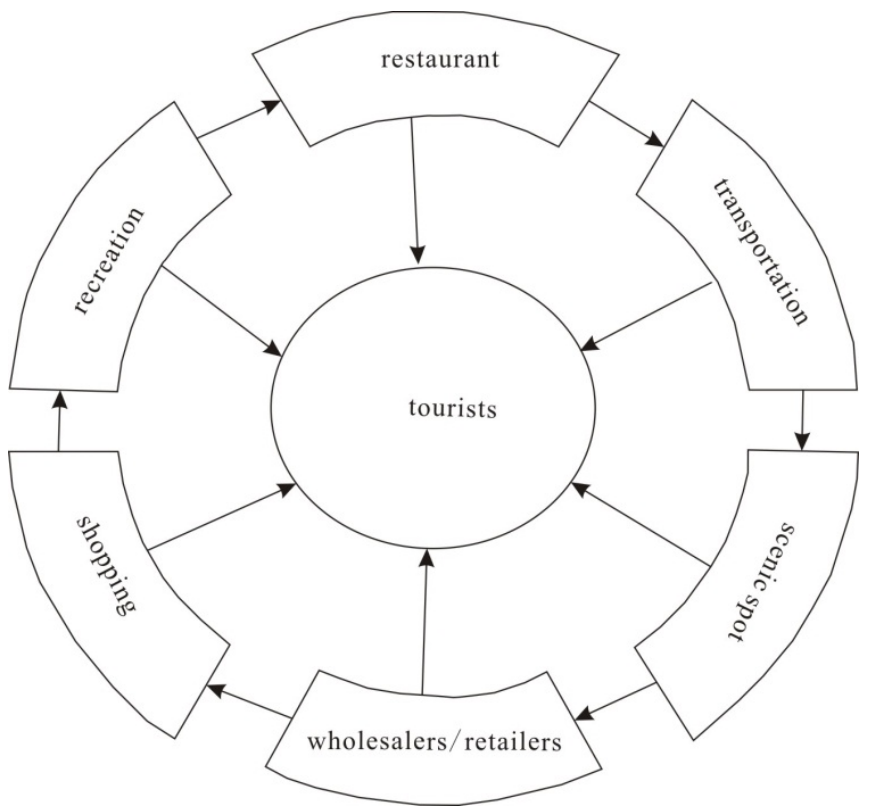

Fig. (5). The supply chain integration of travel industry.

\subsection{The Strategy Integration and Decision-making Mechanism}

Based on strategic alliance of supply chain integration, refers to the destination of the independently established in the market environment of competition cooperation between supply chain strategic alliance, and long-term interests, so as to form a common market and resources, cooperation destination tourism products research and development area of cooperation way. Beijing-Tianjin-Hebei regional tourism destination supply chain strategic alliance, will go beyond general commercial supply chain relationship, between break the regional restrictions, and on the basis of realize, tourist attractions, such as consumer resources optimize the combination, form a rapid response cooperation competition organization with benefit-sharing, risk-sharing.

Supply chain strategy integration is the implementation of the decision-making mechanism construction, the management decision-making information source is no longer limited to a single destination of the supply chain or supply chain network, but in the regional tourism supply chain under the network environment of information exchange and sharing, finally obtained through the analysis of the information is helpful to the decision of the promoting the regional tourism competitiveness.

In Beijing-Tianjin-Hebei regional tourism strategy integration embodies the destination of competitive cooperation strategy, breaks the traditional against competition, as a cooperative game behavior, is conducive to regional tourism destination of reducing overall internal friction and make full use of social resources, its competitive advantages come from each node in the supply chain strategic alliance network of the integration of the core competitiveness.

\subsection{Planning Integration and Cooperation Mechanism}

Planning Integration of regional tourism destination supply chain is between destination at the planning level to implement supply chain strategy alliance, the main instruments of integration including destination docking of supply chain management platform, the construction of a network of supply chain cooperation mechanism and the formation of green supply chain system.

Supply chain management platform can under the support of computer network technology to realize information sharing, business services and has been used in a single destination in the supply chain and the public service supply chain integration. Decision-making mechanism based on strategic alliance of supply chain, regulators in BeijingTianjin-Hebei region of the supply chain need to master the whole area of the market supply and demand information to make decisions, therefore, realization of Beijing-TianjinHebei seamless docking between the respective supply chain management platforms, is the material basis of the integration of supply chain strategy. At the same time, based on the environment of tourism based on sex, ecological construction of the system of supply chain should be extended to the whole of regional tourism cooperation among supply chain, the regional integration of supply chain planning guidelines and supervision and constraint measures, provide institutional guarantee for the sustainable development of regional tourism industry.

\subsection{Operation Integration and Incentive Mechanism}

Regional tourism destination eventually must implement the integrated supply chain strategy and planning integration to the actual operation level, namely each node on the network of supply chain enterprises and service sector managers must first realize that it's role in the supply chain, to the final 
customer demand as the center, through the optimization of the collaborative strategy, in order to improve core competence as the goal, the realization of ultimate value creating and sharing as a whole.

From the point of integration of the Beijing-TianjinHebei region tourism supply chain operation, cannot leave the related incentive mechanism. Incentive mechanism mainly includes two aspects: one is the government's policy incentives, encourage each node in the supply chain enterprises and service departments comply with the supply chain strategic alliance agreement and planning system, reduce speculative risk of the enterprise, enhance the capacity of the solution of the conflict; The second is the establishment of the market incentive mechanism, which is more important on the one hand, through the demand mechanism, cost, price mechanism, reaction mechanism, interest mechanism and risk mechanism to promote the supply chain and the service department to optimize the internal value chain, deepening a collaborative relationship with the supply chain upstream and downstream, to strengthen the weak link of the industry supply chain, eventually release the overall efficiency.

\section{CONCLUSION}

With the narrowing gap of Beijing-Tianjin-Hebei region economy, the regional industrial gradient effect is diminishing, which makes its development from the industrial gradient transfer mode to industry collaboration mode transformation. In the Beijing and Tianjin as the "dual-core" of Bohai economic circle, it will combine the of advantages Beijing and Tianjin port with Hebei resource advantage, and promoting Beijing-Tianjin-Hebei forms infrastructure connection as soon as possible, supporting pillar industries, emerging industries build, general industries complementary industry cluster development pattern and the collaboration of gradient, on the basis of the formation of reasonable industrial layout, industrial division of labor and industry spread, which is an indispensable important part of the integration of the Beijing-Tianjin-Hebei region, also is the basic way to improve the regional competitiveness. In the development of tourism destination, destination marketing have played an important role in attracting, attract customers, and how to provide high quality for the visiting tourists high value of tourism products, make its expected is consistent with the perception of tourism experience, become a big challenge for destination management. As a tentative discussion, in this paper, there are still many deficiencies, such as not enough very clear on the analysis of the dynamic mechanism of sup- ply chain integration, we hope that it will play the important role, and obtain wide and practical value for the research of tourism supply chain.

\section{CONFLICT OF INTEREST}

The authors confirm that this article content has no conflict of interest.

\section{ACKNOWLEDGEMENTS}

This work is supported by The Research on the Performance Evaluation and Promotion Strategy of Beijing-tianjinhebei Tourism Industry Cluster Based on Supply Chain (The Scientific Research Project of Colleges and Universities in Hebei Province in 2015) (Project number: SQ152021); The Research on the organization and operation of Tourism Industry Cluster Based on Supply Chain-An Example of Beijing-tianjin-hebei Tourism Industry Cluster (The Project of China Society of Commodity Science In 2015) (Project number: SPXH201519).

\section{REFERENCES}

[1] Y. Yilmaz, and U. Bititci, "Performance measure-ment in the value chain: manufacturing v. tourism,"International Journal of Productivity and Per-formance Management, (5): 371 389.

[2] M. Harris, and A. Raviv, "The theory of capital structure,"Journal of Finance, vol. 46, no. 1, pp. 297 -355, 1991.

[3] A. Shleifer, and W. Robert, "Liquidation values and debt capacity: a market equilibrium approach," Journal of Finance, vol. 47, no. 4, $1343-1366,1992$.

[4] J. Kornai, "Economics of shortage.amsterdam: North Holland," 1980.

[5] Z. Xinyan, S. Haiyan, and Q. George, "Huang tourism supply chain management: a new research a-genda," Tourism Management, vol. 30, pp. 345-358, 2009.

[6] H. Lucheng, "The macroscopic theory mode research of regional innovation system," China Soft Science, vol. 1, pp. 95-98, 2002.

[7] D. Hongwei, "Regional industry transfer research," Beijing: China's prices press, 2003.

[8] C. Xiaoyong., "Beijing-Tianjin-Hebei industry gradient transfer and Hebei dislocation development," Journal of Hebei Province, vol. 6 , pp. 11-25,2004.

[9] Y. Hualong, and L. Jinping, "Supply Chain Management," Dalian: northeast university of finance and economics press, 2007.

[10] C.Y. Hua, and P. Chichun, "Supply Chain Management and Virtual Industrial Chain," Beijing: science press, 2004.

[11] Z. Xiaoming, and Z. Hui, "On some part of the tourism service supply chain coordination," Urban Development Research, vol. 5, pp. 139 - 143. 2008

[12] S. Yang, Q. G. Huang, H. Song, L. Liang, "Game-theoretic approach to competition dynamics in tourism supply chains," Journal of Travel Research, vol. 47, pp. 425-439, 2011. 